\title{
O atendimento educacional especializado nas salas de recursos multifuncionais da educação infantil
}

\author{
Josiane Beltrame Milanesi* \\ Fabiana Cia**
}

\section{Resumo}

Este estudo objetivou descrever e analisar o trabalho de profissionais atuantes em salas de recursos multifuncionais (SRM) da Educação Infantil em um município de médio porte do interior do Estado de Sáo Paulo. Metodologicamente trata-se de um estudo qualitativo baseado na perspectiva da pesquisa exploratória. Para coleta de dados participaram seis professoras que responderam um roteiro de entrevista composto por 24 questóes. As entrevistas foram gravadas e transcritas. Os dados obtidos foram analisados qualitativamente a partir de eixos e categorias de análise emergidos do contexto pesquisado. Como resultados constatou-se que a atual política de educação inclusiva proposta pelo Governo Federal foi implantada no município com a tentativa de, sempre que possível, seguir o que está disposto na legislação. Apesar disso, há complicaçóes para se realizar um Atendimento Educacional Especializado (AEE) de qualidade. Espera-se que os resultados desta pesquisa contribuam para o entendimento do trabalho que vem sendo realizado nas SRM voltadas para o público da Educação Infantil.

Palavras-chave: Educação infantil; Atendimento educacional especializado; Sala de recursos multifuncionais.

* Doutora em Educaçăo Especial pela Universidade Federal de São Carlos, São Carlos, São Paulo, Brasil.

** Professora doutora do departamento de Psicologia da Universidade Federal de São Carlos, São Carlos, São Paulo, Brasil. 


\section{Specialized educational service in multifunctional resources classrooms of the early childhood education}

\section{Abstract}

This study aimed to describe and analyze the work of professionals working on multifunctional resources classroom of early childhood education in an average municipality in São Paulo. This is a qualitative study based on an exploratory research and it has included six teachers who were interviewed through 24 questions. The interviews were recorded and transcribed. The data were analyzed through the axes and categories that have emerged from the research context. The results demonstrated that the current inclusive educational policies proposed by the Federal Government were established in an attempt to follow what is stated by law. However, there are complications to conduct a specialized educational service of quality. It is expected that the results of this research contribute to the understanding of work that has been done in the multifunctional classrooms to the early childhood education.

Keywords: Early childhood education; Specialized educational service; Multifunctional resource classrooms.

\section{Introdução}

A partir da Constituição Federal, observa-se de modo mais efetivo que a política educacional brasileira voltada para Educação Especial tem priorizado que o ato de estudar seja um direito extensivo a todos, abrangendo também sujeitos que apresentem deficiências (de ordem sensorial, física ou intelectual), transtornos globais do desenvolvimento, bem como aqueles com altas habilidades/superdotação ${ }^{1}$.

O artigo 208 da Constituição, inciso III, especifica que "O dever do Estado com a educação será efetivado mediante a garantia de [...] atendimento educacional especializado aos portadores de deficiência, preferencialmente na rede regular de ensino" (BRASIL, 1988, p. 43). Assim, foi na Constituição Federal que apareceu pela primeira vez a garantia do atendimento educacional especializado (AEE) aos que dele necessitassem.

Neste movimento foi publicada a Resolução CNE/CEB no 02/01. Ao mencionar o atendimento voltado aos alunos com necessidades educacionais especiais, versa no parágrafo único, art. $1^{\circ}$, que:

O atendimento escolar desses alunos terá início na educação infantil, nas creches e pré-escolas, assegurando-lhes os serviços de educação especial sempre que se evidencie, mediante avaliação e interação com a família e a comunidade, a necessidade de atendimento educacional especializado. (BRASIL, 2001, p. 1).

O conceito de AEE vem sendo estruturado. $\mathrm{Na}$ atual política nacional de Educação Especial, as salas de recursos multifuncionais (SRM) têm sido o lócus pre- 
ferencial de oferta do AEE. Esta política prevê que "do nascimento aos três anos, o atendimento educacional especializado se expressa por meio de serviços de estimulação precoce, que objetivam otimizar o processo de desenvolvimento e aprendizagem em interface com os serviços de saúde e assistência social" (BRASIL, 2008, p.10).

Foi sancionada a Lei no 12.796/13 trazendo em seu art. 6º que "É dever dos pais ou responsáveis efetuar a matrícula das crianças na educação básica a partir dos 4 (quatro) anos de idade" (BRASIL, 2013, p. 02). Desta forma, os pais ficam responsáveis por matricularem seus filhos a partir dos quatro anos e não mais a partir dos seis de idade como era até então.

Admite-se que é na Educação Infantil que os sujeitos "[...] desenvolvem as bases necessárias para a construção do conhecimento e desenvolvimento global [...]" (BRASIL, 2008, p. 10), assim, torna-se ainda mais necessário investigar esta etapa de ensino.

$\mathrm{Na} 26^{\mathrm{a}}$ Reunião Nacional dos Pesquisadores em Educação (ANPED) foi encomendada uma pesquisa do grupo de trabalho de Educação Especial (GT 15) (BUENO; FERREIRA, 2003) elegendo como uma de suas prioridades temáticas voltadas a avaliação em âmbito nacional das políticas públicas na área. A este respeito Victor afirma:

Nota-se que no texto da Lei e dos documentos oficiais há tentativa de adequação, mas quando a investigação é realizada nas instituiçóes de ensino as questóes enfrentadas revelam o desencontro entre a política para a educação especial na perspectiva da inclusão, em particular, no contexto da educação infantil. (VICTOR, 2009, p. 4).

Victor (2009) chama atenção pelo fato de não se tratar de uma pesquisa voltada para análise de documentos focalizando as necessidades educacionais especiais no contexto da Educação Infantil, ainda assim, os dados sinalizaram que não há uma diferenciação na legislação educacional voltada para as crianças.

São poucos os estudos que versam sobre a temática do AEE na Educação Infantil, a partir destas constataçôes, esta pesquisa teve por objetivo descrever e analisar o trabalho de profissionais atuantes em SRM da Educação Infantil em um município de médio porte do interior do Estado de São Paulo.

\section{Percursos metodológicos}

Tratou-se de estudo qualitativo baseado na perspectiva da pesquisa exploratória. O instrumento utilizado na coleta de dados foi um Roteiro de entrevista composto por 24 questôes com o objetivo compreender a atuação do profissional da SRM. O roteiro de entrevista foi elaborado com base em instrumentos já existentes (CIA; BARHAM, 2005; FONTES, 2009; SANT'ANA, 2005).

As entrevistas duraram em torno de 30 minutos cada e as respostas foram devidamente audiogravadas e transcritas. Com a leitura foi possível organizar o conjunto de informaçôes em três eixos temáticos e categorias de análise. 
Em relação aos dados das participantes ${ }^{2}$, no conjunto, foram entrevistadas seis $^{3}$ professoras de SRM atuantes em unidades escolares que compóe o sistema público de ensino, tendo como foco o trabalho realizado no AEE com alunos da Educação Infantil. Cabe ressaltar que, estas seis professoras representou o número total de profissionais atuantes em SRM da Educação Infantil concursadas no município.

\section{Análise e discussão dos resultados}

Primeiramente, para esclarecer um pouco acerca do município pesquisado, informa-se que o mesmo se localiza no interior do estado de Sáo Paulo, sendo sua população estimada em 186.253 habitantes cobrindo uma área de $499 \mathrm{~km}^{2}$ (IBGE, censo demográfico 2010). O sistema público de ensino é composto de escolas municipais (oferecendo Educação Infantil, Ensino Fundamental e Educação de Jovens e Adultos) e estaduais (oferecem o Ensino Fundamental de $6^{\circ}$ ao $9^{\circ}$ ano e Ensino Médio).

Em 2013, ano de realização deste estudo, havia no município 37 unidades de ensino com oferta de Educação Infantil atendendo ao todo 7.539 crianças, compreendendo as Etapas I (para crianças de quatro meses a três anos, com 3.494 alunos) e Etapa II (referente ao ensino de quatro e cinco anos, com 4.045 alunos). No que se refere a Educação Infantil, 29 escolas tinham matriculado alunos público-alvo da Educaçáo Especial, contando, ao todo, com dez professores para realizar o AEE. Alunos que possuíam comprovaçáo de alguma especificidade totalizavam 99 alunos atendidos nas SRM. Para além, haviam outros alunos sem diagnóstico fechado ou com necessidades latentes que também eram atendidos. Os resultados deste estudo serão apresentados seguindo os três eixos emergidos dos dados.

\section{Eixo 1 - Sala de recursos multifuncionais}

- Alunos atendidos / formato do atendimento:

Das seis professoras, duas atuavam em mais de uma SRM do município. Todas atuavam em SRM que recebiam alunos da Educaçáo Infantil (EI) e do Ensino Fundamental (EF). O quadro 1 apresenta o número e as especificidades dos alunos atendidos:

Quadro 1

\begin{tabular}{|c|c|c|c|c|c|c|}
\hline Professora & $\begin{array}{c}\text { Alunos } \\
\text { da EI }\end{array}$ & $\begin{array}{c}\text { Alunos } \\
\text { do EF }\end{array}$ & $\begin{array}{c}\text { Alunos em } \\
\text { avaliação } \\
\text { da EI }\end{array}$ & $\begin{array}{c}\text { Alunos da } \\
\text { EI sem } \\
\text { deficiência }\end{array}$ & $\begin{array}{c}\text { Especificidades } \\
\text { dos alunos da } \\
\text { EI atendidos }\end{array}$ & $\begin{array}{c}\text { Formato do } \\
\text { atendimento }\end{array}$ \\
\hline 1 & 6 & 8 & 3 & 0 & $\begin{array}{c}\mathrm{SD}^{4} \text {; Alteraçáo } \\
\text { cromossômica; } \\
\text { Deficiência } \\
\text { múltipla. }\end{array}$ & $\begin{array}{c}\text { Individual; } \\
\text { duas vezes } \\
\text { por semana; } \\
\text { duraçáo de } \\
50 \text { minutos. }\end{array}$ \\
\hline
\end{tabular}


Continuação do Quadro 1

\begin{tabular}{|c|c|c|c|c|c|c|}
\hline 2 & 14 & 11 & 4 & 2 & $\begin{array}{l}\text { Hidrocefalia; } \\
\text { Baixa visão; } \\
\text { Atraso neurop- } \\
\text { sicomotor; PC5; } \\
\text { SD. }\end{array}$ & $\begin{array}{c}\text { Uma vez } \\
\text { por semana; } \\
\text { duração de } \\
1 \text { h40. }\end{array}$ \\
\hline 3 & 8 & 17 & 1 & 0 & $\begin{array}{l}\text { Síndrome de } \\
\text { Cri Du Chat; } \\
\text { Baixa visão; } \\
\text { DI }{ }^{6} \text {; PC. }\end{array}$ & $\begin{array}{c}\text { Individual e/ } \\
\text { ou coletivo; } \\
\text { uma ou } \\
\text { duas vezes } \\
\text { por semana. } \\
\text { Se uma vez, } \\
\text { duração de } \\
2 \mathrm{~h} 30 .\end{array}$ \\
\hline 4 & 10 & 17 & 3 & 0 & $\begin{array}{l}\text { DI; Deficiência } \\
\text { múltipla; } \\
\text { Autismo; DF7. }\end{array}$ & $\begin{array}{c}\text { Duas vezes } \\
\text { por semana; } \\
\text { duraçáo de } \\
50 \text { minutos. }\end{array}$ \\
\hline 5 & 7 & 17 & 2 & 0 & $\begin{array}{l}\text { Deficiência } \\
\text { múltipla; } \\
\text { Síndrome de } \\
\text { Charge; SD. }\end{array}$ & $\begin{array}{c}\text { Duas vezes } \\
\text { por semana; } \\
\text { duraçáo de } \\
50 \text { minutos. }\end{array}$ \\
\hline 6 & 6 & 4 & 0 & 1 & $\begin{array}{c}\text { Síndrome de } \\
\text { West; TGD }{ }^{8} \text {; } \\
\text { PC; DI. }\end{array}$ & $\begin{array}{c}\text { Duas vezes } \\
\text { por semana; } \\
\text { duraçáo de } \\
1 \text { h. }\end{array}$ \\
\hline
\end{tabular}

Fonte: dados de pesquisa

Analisando o quadro nota-se que não havia uma regra estabelecida em relação ao número de alunos recebidos por cada profissional. Seguindo o exemplo das professoras participantes, o número mínimo de alunos considerando a Educação Infantil e o Ensino Fundamental variou entre 10 e 27. $\mathrm{O}$ mesmo pode-se concluir ao analisar somente os alunos pertencentes a Educação Infantil, em que o número variou entre seis e 14 .

Voltando-se para as especificidades dos alunos da Educação Infantil, concluise que seguindo as normativas legais, as profissionais trabalhavam com os mais diversos tipos de deficiências e transtornos globais do desenvolvimento. Verificou-se que as profissionais recebiam nas SRM alunos com outras especificidades e, ainda, que estavam em avaliação ou mesmo que não possuíam deficiência. Esses alunos, segundo a legislação referente ao AEE, não poderiam estar matriculados nas SRM, porém, eles eram autorizados pelo município.

Reportando-se ao formato do atendimento, parece que as profissionais decidiam qual era a melhor maneira de organizá-los podendo este variar de acordo com 
a quantidade de alunos frequentando cada SRM. No geral, os alunos recebiam no mínimo $1 \mathrm{~h} 40$ de atendimento por semana. Esta independência conferida as profissionais pode vir a acarretar em diferenciaçóes no atendimento em termos de qualidade, pois enquanto pode faltar atendimento para alguns, outros podem se beneficiar estando mais tempo na SRM.

- Critérios de elegibilidade:

Todas profissionais, ao serem indagas sobre quais eram critérios para frequentar a SRM, responderam que era necessário ter um laudo. Uma professora disse que o aluno poderia ter um atraso no desenvolvimento ou um atraso cognitivo para receber o AEE. Outra professora disse que poderia ter também a indicação de uma instituição da saúde apontando a necessidade de frequentar a SRM.

Para deixar de frequentar, todas as professoras disseram que se o aluno possuísse uma deficiência nunca ocorreu de suspender o AEE. Uma professora informou que para isso ocorrer seria somente se a família não aceitasse e não levasse mais a criança.

- Materiais advindos do MEC ou adquiridos:

As respostas voltadas para os materiais existentes nas SRM foram variadas. Cada professora citou diferentes produtos e como eles chegaram até as salas em que atuam. Todas afirmaram ter muitos jogos.

Uma professora contou ter muitos livros de texturas e musicais e fazer uso de massinha, giz de cera, dobraduras, dentre outros. Disse ainda, que os materiais existentes não vieram no kit do MEC da SRM, mas que foram adquiridos com verba do MEC e ela mesma fez a compra.

Referindo-se aos materiais advindos do MEC, duas professoras afirmaram ter: jogo da memória com textura, caixa sensorial, bandinha, jogos de encaixe e bloco lógico, mas que materiais específicos para trabalhar com a Educação Infantil não vieram.

Voltando-se então para os materiais existentes nas SRM para o atendimento ao público da Educação Infantil, conclui-se que em grande parte eles não advieram do kit enviado pelo MEC. Isso é problemático, pois nesta fase o trabalho se mostra fundamental para o desenvolvimento das crianças.

- Função:

Em relação a função desempenhada as respostas foram diversas, porém, a grande maioria, concorda que a funçáo é orientar o professor da classe comum, o monitor', a equipe gestora, funcionários da escola e familiares. As profissionais relataram ser incumbência delas, atender as crianças colaborando em seu crescimento, trabalhando dentro dos objetivos de desenvolvimento de habilidades e fazendo avaliaçóes. Este trabalho deve ainda ocorrer em paralelo junto a sala de aula comum para que os objetivos sejam os mesmos, sendo eles: confeccionar material e recursos, trabalhar na suplementação e complementação no contra turno, avaliar o aluno e 
construir juntamente com o professor do ensino comum o Plano de Desenvolvimento Individual (PDI).

- Avaliação

$\mathrm{Na}$ categoria avaliação dividiu-se o relato das participantes em avaliação diagnóstica, que é voltada para identificação da deficiência e, avaliação pedagógica, realizada pelas profissionais atuantes nas SRM. Referindo-se a avaliação diagnóstica, por não haver no roteiro de entrevista questóes específicas, o que se destacou foram pontos levantados de forma aleatória.

Foi possível identificar que havia no município a Associação de Pais e Amigos dos Excepcionais (APAE) que era uma das instituiçóes que emitia laudos. Três questôes foram suscitadas aludindo acerca da dificuldade na emissão de laudo. A primeira voltou-se para algumas famílias que eram resistentes e insistiam em não procurar profissionais para acompanhar o filho e emitir o laudo, quando fosse o caso. Outro ponto foi o fato de chegarem alunos com características tão raras que muitas vezes o laudo demorava a sair ou acabava nem sendo emitido. Ocorria ainda, de terem profissionais responsáveis pela emissão de laudos que eram resistentes a emissão por acharem não ser importantes para as escolas.

Acerca do diagnóstico clínico como critério de elegibilidade para frequentar a SRM, as orientaçóes para o preenchimento do Censo Escolar/MEC/INEP em 2011 não cobram que o aluno tenha este tipo de diagnóstico.

[...] é necessário que o professor do Atendimento Educacional Especializado - AEE elabore o plano de AEE para, a partir de entáo, organizar e ofertar o devido atendimento ao estudante público-alvo da educação especial. Logo elaborará pareceres que terão validade [...] é importante notar que o Censo escolar é a base de dados da educação, cuja ações não prescindem de laudo médico para serem efetivadas. (INEP, 2011, p. 6-7).

Reportando-se a avaliação pedagógica, as professoras informaram não haver uma avaliação única e padronizada para a Educação Infantil. Uma professora levantou a necessidade de que haja uma avaliaçáo deste tipo e que conversas estavam sendo realizadas para a efetivação deste desejo. Para acompanhar o desenvolvimento dos alunos, as professoras informaram fazer uma avaliação de forma descritiva no início e no final do ano que culminava num relatório final contendo o quanto o aluno avançou no decorrer do processo.

\section{Eixo 2 - Professor do atendimento educacional especializado \\ - Busca por informaçôes}

Ao serem indagadas sobre a necessidade e o local de realização de buscas por informaçóes sobre as especificidades dos alunos, as participantes relataram que procuravamm sempre que necessário. Dentre os locais, a internet foi citada por todas as participantes. O segundo local mais acessado foram livros e profissionais da saúde quando desconheciam alguma síndrome, por exemplo, ou quando as informaçóes 
constantes nos laudos não eram claras. Além destes meios, relataram fazer buscas em revistas, com os familiares e outros colegas da área. Ressalta-se ainda a opinião de uma professora que fez uso de livros disponibilizados pelo MEC, assim como artigos científicos, afirmando que estes não ajudam na prática.

Foi possível perceber que as participantes do estudo estavam sempre em busca de informações que possibilitassem à elas desenvolverem um trabalho mais efetivo com seus alunos, sendo que esta tentativa se dava através de formaçóes continuadas e pesquisas.

- Adaptaçōes realizadas

Sobre as adaptaçóes necessárias para atender as especificidades dos alunos, todas as participantes relataram ser preciso realizar adequaçôes e são elas mesmas que faziam ou buscavam ajuda quando necessário. De modo geral, as adaptaçôes eram realizadas de acordo com as demandas. Essas necessidades variavam devido ao fato de ter determinado aluno na SRM e do material utilizado. Por se tratar da Educação Infantil, uma professora relatou que só houve necessidade de adaptar materiais para uso na SRM, pois na sala comum o trabalho era voltado para o lúdico.

Dentre as adaptaçóes, as professoras relataram terem feito algumas de baixo custo como colocação de imã, engrossamento de lápis, ampliaçáo de material para deficientes visuais, materiais com diferentes texturas e, para além dessas, outras adaptaçôes mais complexas que demandavam trabalho de outros profissionais, tendo como exemplo mesas com recortes, mesa e cadeira na altura correta para criança, apoio para os pés e inclinação, prancha inclinada, dentre outras. Uma profissional disse ter feito uso da verba do Programa Dinheiro Direto na Escola (PDDE) e também de doaçóes. Três professoras relataram ainda contar com o auxílio da monitora para realizar as adaptaçôes.

Neste item, foi interessante ouvir o relato de uma professora que produziu uma cadeira de papelão para sua aluna poder sentar mais 'embaixo' ficando assim mais próxima dos alunos de sua turma. Exalta-se o trabalho das profissionais em querer buscar adaptaçóes que auxiliem no desenvolvimento educacional dos alunos.

- Atividades de ensino

Ao serem indagadas sobre quais eram os procedimentos metodológicos utilizados, as respostas foram variadas, mas unânimes em relação ao fato de não usarem uma única metodologia. De modo geral, as atividades eram de escrita, trabalho com cores e formas, estimulação sensorial, coordenação motora, atividades de vida diária, atividades lúdicas, dentre outras. Para a realização das atividades as professoras descreveram fazer uso de imagens, bloco lógico, jogos, brincadeiras, faz de conta e sempre que possível com material concreto. A Resolução no $04 / 09$ ao se referir as atribuições do professor do AEE indica: "elaborar e executar plano de Atendimento Educacional Especializado, avaliando a funcionalidade e a aplicabilidade dos recursos pedagógicos e de acessibilidade" (BRASIL, 2009, p. 03). Neste sentido, a cartilha "A Educação Especial na Perspectiva da Inclusão Escolar: a escola comum inclusiva" (ROPOLI 
et al., 2010) dispóe que a discussão dos planos de AEE deve ocorrer com todos os membros da equipe escolar e, ainda, que podem ser criadas parcerias com setores da comunidade para a implementação destes planos.

Desta forma, a partir dos dados emergidos, parece não haver um plano de AEE sistematizado e construído da forma indicada nos documentos oficiais. Porém, há que se destacar que muitas vezes determinaçôes políticas não levam em consideração a realidade vivida por profissionais da educação que encontram dificuldades no cumprimento de determinadas orientaçóes.

- Dificuldades encontradas

As respostas acerca das dificuldades encontradas foram variadas. Segundo as profissionais, os professores da classe comum têm dificuldades para entender o público que deve ser atendido nas SRM, encaminhando alunos com problemas de comportamento ou dificuldades de aprendizagem. Outra questão foi o fato de alguns professores ainda não aceitarem a inclusão, chegou a ocorrer algumas vezes a não aceitar a presença do professor especializado na sala de aula. Surgiu ainda a falta de formação dos educadores ser a maior dificuldade encontrada.

Uma professora levantou a questão referente a verba, pois o fato de não ter dinheiro em mãos para adquirir material e pagar serviços de outros profissionais dificulta o trabalho. Esta relata: "[...] se tivesse o dinheiro mais fácil na mão ficaria muito mais fácil. Porque você vai até o marceneiro, se a prefeitura tivesse o marceneiro seria tudo mais fácil, rápido, o recurso chegaria tudo mais fácil na nossa mão" (PROFESSORA 3).

Algumas questóes giraram em torno dos responsáveis dos alunos que recebiam o atendimento nas SRM. Uma professora disse ter famílias que não aceitavam o atendimento, não levavam os filhos, o que acabava gerando confusão. Outra afirmou que algumas famílias queriam 'jogar a responsabilidade' para os professores: "ah, mas ele toma remédio, eu não consigo dar, então vou mandar para escola” (PROFESSORA 4). E ainda, em relação as famílias, uma outra questão girou em torno da dificuldade de realizar trocas, pois algumas não frequentavam as escolas e não seguiam as orientaçôes recebidas.

\section{Eixo 3 - Convivência/relacionamento com demais atores \\ - Professores do ensino comum}

Nesta categoria, dividiu-se o relato das participantes em três pontos diferentes. $\mathrm{O}$ primeiro deles refere-se as açóes desenvolvidas junto ao professor do ensino comum, grande parte das profissionais disseram propiciar orientaçóes. Dentre as atividades realizadas, foi citada a construção de atividades adaptadas. Uma professora especializada disse levar artigos de revistas que trouxessem contribuiçóes para a prática para os docentes e tentava a partir do que leram construir atividades em conjunto. Uma professora informou que procura ir ao turno inverso para ter contato com o professor e entrar na sala de aula. Como faz uma orientação mais ampla no início 
do ano, nessas oportunidades verifica quais são as demandas dos professores. Outros momentos possíveis para trocas é a Hora de trabalho pedagógico coletivo (HTPC) e o Horário de Trabalho Pedagógico Individual (HTPI), porém, somente duas professoras citaram estes espaços.

Outra questão foi sobre as informaçôes úteis a respeito dos alunos que recebiam atendimento nas SRM através do professor do ensino comum, todas as participantes relataram ter as informaçôes necessárias. Uma professora citou que, de modo geral, os professores da Educaçáo Infantil não têm resistência em ter alunos com deficiências, por isso as informaçôes necessárias eram tidas sem maiores problemas.

Por fim, acerca de sugestóes para melhorar a relação entre esses dois profissionais, quatro participantes indicaram a necessidade de um momento específico para realização de encontros, pois geralmente o que ocorrem são 'conversas de porta'. Uma professora citou ainda que, para isso ocorrer, seria necessária a interferência da gestão escolar.

Acredita-se que a gestão escolar deva propiciar oportunidades para que profissionais atuantes em SRM e em salas de ensino comum se interajam de forma apropriada, ou seja, que trabalhem em equipe na troca de informaçôes de forma frequente e participem de momentos específicos para dialogar sobre os alunos construindo possibilidades de desenvolvimento educacional efetivas.

- Outras instituiçôes

Ao serem indagadas sobre contatos estabelecidos com outras instituiçóes que o aluno da SRM frequentasse e profissionais que atendessem os alunos, cinco delas responderam que tinham acesso à um centro de habilitação infantil localizado no município. Uma participante assegurou que tinha contato com profissionais deste centro em uma reunião que ocorria no início e outra no fim do ano. Outras afirmaram que tinham bom relacionamento e contato via telefone, redes sociais e que iam ao centro sempre que necessário. A respeito desta instituição é possível ainda o contato via ofício como indicou a fala da professora:

\begin{abstract}
E aí também eu posso solicitar via ofício, requerer para saber se aquela criança está realmente passando por atendimento lá, que foi o que eu fiz com ele, com o Roberto, eu fiz um ofício para o centro perguntando que tipo de atendimento e se ele estava sendo levado para o atendimento, aí elas me responderam tudo que está acontecendo com ele lá. (PROFESSORA 5).
\end{abstract}

Duas profissionais relataram que pediam para o responsável pelo aluno o telefone de profissionais da saúde que atendiam os filhos para que pudessem contata-los, isso ocorria principalmente quando a criança possuía plano de saúde. Concorda-se que a proximidade possível de ser estabelecida entre as instituiçóes e profissionais da saúde nas quais o aluno é assistido e a escola, bem como a família, sáo benéficas quando culminam em uma colaboraçáo que possibilite no desenvolvimento da criança voltado ao ensino. Mas ressalta-se que a falta desta parceria não pode ser impeditivo de uma boa atuaçáo da escola. 
- Família

De modo geral, voltando-se para o relacionamento entre as professoras atuantes nas SRM e as famílias dos alunos as participantes informaram que possibilitavam orientação principalmente em açôes cabíveis de serem feitas em casa que auxiliassem no desenvolvimento dos alunos. Não havia estabelecido momentos pré-definidos para realização de trocas, ocorrendo contatos formais somente quando algo 'de errado' acontecia com a criança e, ocorria ainda, desses contatos serem via telefone.

Outro ponto foi em relação a anamnese que era feita com o responsável pelo aluno, sendo este um momento que a família ia até a escola. Duas professoras afirmaram ter famílias que mentem sobre o filho. Duas outras relataram sentir falta de momentos específicos para atender a família, o que poderia ser benéfico para o desenvolvimento do aluno. Ainda sobre a relaçáo com familiares, uma professora relatou que se ela não procurasse, a família não ia até a escola, pois a escola está sempre aberta a recebê-la. Duas professoras relataram aproveitar o momento do atendimento e de reunióes para realizar trocas.

Com os dados levantados, percebe-se que de modo geral a relaçáo que a escola estabelecia com familiares dos alunos acontecia de forma mais efetiva somente quando houvesse uma exigência para que se estabelecesse este contato (momento da anamnese, reunióes...). Parece não haver esforços para uma compreensão mais ampla da realidade vivida por estes alunos bem como seus familiares.

- Aluno que recebe o AEE e o aluno do ensino comum

Ao serem indagadas sobre o relacionamento entre os alunos que frequentavam a SRM e o aluno do ensino comum, todas as professoras foram unânimes em dizer que não há problemas no convívio entre eles. Trata-se de uma relaçáo de respeito e parceria. "Ah é uma graça. As crianças, elas são muito receptivas, e elas são muito preocupadas com a criança que tem deficiência. Então elas querem ajudar, querem pegar na máo[...]" (PROFESSORA 5). Apenas uma professora ressaltou que dependendo do caso, se for um aluno que tem atitudes agressivas, acaba sendo 'tachado' dentro da sala de aula pelos demais alunos.

\section{Para concluir}

Neste estudo, constatou-se que a atual política de educação inclusiva foi implantada no município pesquisado com a tentativa de, sempre que possível, seguir o que está disposto na legislação. Assim, os professores recebem nas SRM alunos com diferentes idades e demandas e, ainda, um público que vai além do indicado na política, sendo este o local destinado ao AEE, o que nos leva a crer que outros cenários deste atendimento acontecer não mais ocorrem ficando limitado a um único espaço.

Acredita-se que outras formas de atendimento consideradas essenciais para o desenvolvimento humano e, ainda, para o ensino e aprendizagem, estáo sendo restritas somente a SEM, o que se torna fator complicador principalmente se considerarmos que na Educação Infantil a estimulação precoce é de suma importância e, 
como podemos ver nos resultados, pouco foi citada sobre esta prática. Destaca-se que nas atuais legislaçóes voltadas ao AEE (BRASIL, 2008, 2009, 2011) quando aborda aspectos relacionados a Educação Infantil cita somente a estimulação precoce como integrante desta etapa.

Outra problemática, diz respeito aos materiais disponíveis nas SRM e as atividades de ensino realizadas. É de suma importância que sejam disponibilizados materiais diversos adequados a faixa etária das crianças, que por vezes eram confeccionados pelas próprias professoras.

Os procedimentos avaliativos se mostraram frágeis nos relatos das participantes. Parece não haver critérios estabelecidos sobre como deve ocorrer a avaliação contínua e processual dos alunos que seja formativa, ficando este a cargo somente a critério das profissionais, levando a ocorrer de diferentes formas e culminando em um relatório final. Considerando a importância de se acompanhar o desenvolvimento dos alunos, maior atenção deveria ser dispensada ao processo avaliativo.

Um item bastante ressaltado foi a relação estabelecida com a família da criança que recebe o AEE. As participantes destacaram em diversos momentos a necessidade de se estreitar os laços a fim de se alcançar ganhos no desenvolvimento dos alunos. A necessidade de aproximar a família da escola é latente e estratégias para esta interação devem ser pensadas e efetivadas por professores e profissionais da gestáo escolar.

De maneira geral, percebe-se que o trabalho pedagógico voltado a Educação Infantil e todas as especificidades que abarcam esta etapa de ensino parecem não serem considerados nas políticas em nível nacional de Educação Especial, cabendo assim acreditar que há muito mais uma referência para toda a Educação Básica, desprezando as especificidades de cada faixa etária para além de outras características. Cabe destacar ainda, que este estudo fez uso da escuta somente de profissionais atuantes nas SRM, assim, sugere-se que outros estudos sejam realizados integrando outros atores para que se possa ter um panorama mais amplo do atendimento educacional especializado.

\section{Referências}

BRASIL. Constituiçấo (1988). República Federativa do Brasil: promulgada em 5 de outubro de 1988. 16. ed. atual. ampl. São Paulo: Saraiva, 1997.

Ministério da Educação. Resoluçăo CNE/CEB nº 2, de 11 de setembro de 2001. Institui Diretrizes Nacionais para Educação Especial na Educação Básica/Secretaria de Educação Especial. Brasília. MEC/SEESP, 2001. Disponível em: <portal.mec.gov.br/seesp/arquivos/pdf/diretrizes.pdf>. Acesso em: 10 mar. 2010.

BRASIL. Ministério da Educaçẫo. Política Nacional de Educaçăo Especial na Perspectiva da Inclusão Escolar, 2008. Secretaria de Educação Especial. Disponível em: <portal.mec.gov.br/seesp/arquivos/pdf/politica.pdf>. Acesso em: 20 mar. 2010.

Ministério da Educaçáo. Resoluçáo no 4, de 02 de outubro de 2009. Institui Diretrizes Operacionais para o Atendimento Educacional Especializado na Educação Básica, modalidade Educação Especial. Secretaria de Educação Especial. Disponível em: <portal.mec.gov.br/dmdocuments/rceb004_09.pdf>. Acesso em: 30 nov. 2010.

Ministério da Educação. Decreto no 7.611, de 17 de novembro de 2011. Dispóe sobre a educação especial, o atendimento educacional especializado e dá outras providências. Presidência da República. Casa Civil. Disponível em: <www.planalto.gov.br/ccivil_03/_Ato2011-2014/2011/Decreto/D7611.htm>. Acesso em: 05 dez. 2012. 
BRASIL. Ministério da Educaçấo. Lei no 12.796, de 04 de abril de 2013. Altera a Lei no 9.394, de 20 de dezembro de 1996, que estabelece as diretrizes e bases da educação nacional, para dispor sobre a formação dos profissionais da educação e dar outras providências. Presidência da República. Casa Civil. Disponível em: <http://blogproinfanciabahia.wordpress.com/2013/04/05/lei-12-796-de-4-de-abril-de-2013-sancionada-pela -presidente/. Acesso em: 09 mai. 2013.

BUENO, J.G. S.; FERREIRA, J.R. (coord.). Políticas regionais de educação especial no Brasil. In: Reunião anual da associaçáo nacional de pós-graduação e pesquisa em educaçáo. 26a , Poços de Caldas, 2003.

CIA,F.; BARHAM, E. J. Comportamentos dos professores frente a alunos com necessidades educacionais especiais. In: Encontro regional do international council on education for teaching, 2005, São Carlos. Anais do Encontro Regional do International Council on Education for Teaching. São Carlos: EDUFSCar, 2005. p. 1-9.

Instituto Brasileiro de Geografia e Estatística. Censo Demográfico 2010. Disponível em: < http://www.censo2010.ibge.gov.br/>. Acesso em: 02 mar. 2014.

Instituto Nacional de Estudos e Pesquisas Educacionais Anísio Teixeira (INEP). Educacenso 2011. Disponível em: <www.inep.gov.br>. Acesso em 01 abr. 2014.

ROPOLI, E. A. et al. A Educaçáo Especial na Perspectiva da Inclusáo Escolar: a escola comum inclusiva. Brasília: Ministério da Educação, Secretaria de Educação Especial; [Fortaleza]: Universidade Federal do Ceará, 2010.

VICTOR, S. L. Sobre inclusão, formação de professores e alunos com necessidades educacionais especiais no contexto da educação infantil. In: Simpósio brasileiro de política e administraçáo da educaçáo, 24, 2009, Vitória. Anais do Simpósio Brasileiro de Política e Administração da Educação. Vitória, 2009. CD-ROM.

\section{Notas}

${ }^{1}$ No decorrer da história, as pessoas que possuem alguma característica peculiar associada a uma limitação (sensorial, física ou intelectual) têm recebido diferentes denominaçôes. Atualmente, segundo as normas oficiais, são chamadas de pessoas com deficiência, transtornos globais do desenvolvimento e altas habilidades/superdotaçăao. Essas pessoas são consideradas, atualmente, o público-alvo da Educaçăo Especial.

${ }^{2}$ Optou-se por utilizar artigo feminino ao se reportar as participantes pelo fato de todas serem do referido sexo.

${ }^{3}$ A coordenadora de Educação Especial do município em questão, ao ser informada sobre a pesquisa, pontuou que gostaria que somente as profissionais concursadas participassem.

${ }^{4}$ Síndrome de Down.

${ }^{5}$ Paralisia cerebral.

${ }^{6}$ Deficiência Intelectual.

${ }^{7}$ Deficiência física.

${ }^{8}$ Transtorno global do desenvolvimento.

${ }^{9}$ Cargo ocupado por pessoas que possuem Ensino Médio atuantes juntamente com o público-alvo da Educação Especial. Possuem uma carga horária de oito horas por dia tendo como função cuidar da parte higiênica e da alimentação (quando for o caso), além de apoiar no trabalho pedagógico.

\section{Correspondência}

Josiane Beltrame Milanesi - Rua São João, no 28 - Campo Grande, Cariacica. CEP: 29.146-630 - Espírito Santo, Brasil.

E-mail: milanesi.josiane@gmail.com - fabianacia@hotmail.com

Recebido em 22 de julho de 2015

Aprovado em 21 de janeiro de 2016 
